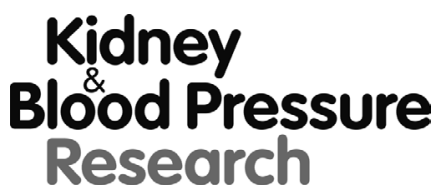

Kidney Blood Press Res 2018;43:938-950

DOI: $10.1159 / 000490473$

Publisned oninne: IZ June, 2018

Accepted: 30 May, 2018

This article is licensed under the Creative Commons Attribution-NonCommercial-NoDerivatives 4.0 InternaThis article is licensed under the Creative Commons Attribution-NonCommercial-NoDerivatives 4.0 Interna-
tional License (CC BY-NC-ND) (http://www.karger.com/Services/OpenAccessLicense). Usage and distribution tional License (CC BY-NC-ND) (http://www.karger.com/Services/OpenAccessLicense). Usage and dist

\title{
Continuous Blood Purification Ameliorates Multiple Organ Failure Through Inhibiting the Activation of the P38 MAPK Signaling Pathway in a Rat Model
}

\author{
Lan Ling ${ }^{\mathrm{a}}$ Qian-Kuan Wen ${ }^{\mathrm{a}} \quad$ Shan-Hong Zhang ${ }^{\mathrm{a}}$ Li-Da Zhia Hong Lib Gang Li $^{\mathrm{a}}$ \\ Wen-Jia Zhang ${ }^{\mathrm{a}}$
}

aEmergency Department, China-Japan Friendship Hospital, Beijing, 'bepartment of Vascular Surgery, Jilin University, Changchun, China

\section{Key Words}

Multiple organ failure $\cdot$ Continuous blood purification $\cdot$ P38 MAPK signaling pathway $\cdot$ INOS - Serum nitric oxide • MAPK

\begin{abstract}
Background/Aims: Multiple organ failure (MOF) is a primary threat to the survival of patients with systemic inflammation. Blood purification is employed in the treatment of MOF, as an artificial kidney or artificial liver. This study focuses on the effects of continuous blood purification (CBP) on ameliorating MOF through regulating the p38 mitogen-activated protein kinase (MAPK) signaling pathway in a rat model. Methods: A rat model of MOF was successfully established by endotoxin injection after hemorrhagic shock resuscitation. The mRNA expressions of inducible nitric oxide synthase (iNOS) and p38 MAPK of liver, kidney, and lung tissues in each group were measured by RT-qPCR at each measuring time point. To evaluate the activation of p38 MAPK signaling pathway, protein levels of phosphorylated p38 (p-p38) MAPK and p38 MAPK was measured by western blot analysis. The serum levels of nitric oxide and TNF- $\alpha$ were determined. Results: After CBP treatment, the levels of SGPT, $S G O T, C r$, and $\mathrm{BUN}$ were significantly declined, while the $\mathrm{PaO}_{2}$ value was increased. Expressions of p38 MAPK mRNA, iNOS mRNA, p-p38 MAPK protein and p38 MAPK protein, and nitric oxide and TNF- $\alpha$ levels were markedly elevated in MOF, an effect blunted by CPB. Meanwhile, pathological sections of liver, kidney, and lung tissues after CPB treatment ameliorated swelling and inflammation. Conclusion: Our study proved that CBP could downregulate the p38 MAPK signaling pathway, suppress iNOS expression, reduced the serum levels of nitric oxide and TNF- $\alpha$, thus ameliorate symptom of MOF.




\section{Kidney Blood Pressure Research}

\section{Introduction}

Multiple organ failure (MOF), a clinical syndrome of two or more organ failure (heart, liver, lung, and kidney) with high morbidity and mortality, is characterized as a sequela to ischemia/reperfusion (I/R) injury, hemorrhage shock, abdominal compartment syndrome (ACS) and infection [1-4]. Hemorrhage is a main cause of shock and preventable death in trauma [5]. During hemorrhagic shock, splanchnic hypoperfusion could result in cellular hypoxia and tissue damage, which further contributes to severe organ failure [6]. Previous studies well documented that I/R injury could promote the production of various reactive oxygen species (ROS), which caused lipid peroxidation, leading to cellular membrane instability and consequently, cell damage [7-9]. Cellular injury facilitated the expressions of tumor necrosis factor- $\alpha$ (TNF- $\alpha$ ) and other inflammatory cytokines, which ultimately led to systemic inflammatory response syndrome (SIRS) and MOF [10]. Besides, endotoxemia has shown significant ability in regulating inducible nitric oxide synthase (iNOS) expression and serum nitric oxide levels [11]. And researchers have also found that MOF caused by endotoxemia seriously affected patients' survival rate [12]. Fortunately, previous studies have proved blood reperfusion might play an important role in restoring intravascular volume and improving the oxygen carrying capacity of blood cells [13,14]. Moreover, blood purification has also shed lights on the treatment of MOF recently due to its capabilities of removing of toxic substances and inflammatory cytokines and maintaining of the stability of hemodynamics [15]. According to a previous study, continuous blood purification (CBP) could ameliorate the prognosis of patients who suffer from MOF, but the exact mechanisms were still unclear [16].

Mitogen-activated protein kinases (MAPKs), including p38 MAPK, c-Jun N-terminal kinases (JNKs) and extracellular signal-regulated kinases (ERKs), were critical components of the signaling transduction system, playing a key role in various cellular responses, such as proliferation, differentiation, and apoptosis $[17,18]$. During hemorrhage shock, MAPKs showed remarkable ability to regulate vascular reactivity [19]. Besides, p38 MAPK signaling pathway, associated with I/R injury, was found to be a potential target for prevention and treatment of tissue injury $[20,21]$. Therefore, the alleviation of circulatory shock and MOF induced by the inhibition of p38 MAPK signaling pathway might cause by the pathway downregulating the expressions of TNF- $\alpha$ and other inflammatory cytokines, as well as suppressing the inflammatory response to endotoxemia subsequently [22]. In our study, we focused on investigating the effects of CBP on ameliorating MOF via the p38 MAPK signaling pathway in a rat model.

\section{Materials and Methods}

\section{Experimental animals and ethics statement}

A total number of 90 Sprague Dawley (SD) rats of 6 weeks old (Shanghai SLAC Laboratory Animal Co., Ltd., Shanghai, China) were housed in separated cages under specific pathogen free (SPF) conditions, at room temperature $\left(25 \pm 3^{\circ} \mathrm{C}\right)$ and relative humidity $(55 \sim 75 \%)$ with free access to sterile food and water. Their cages were cleaned every two days. All experiments were performed in accordance with the rules and regulations of the Animal Care and Use Committee and the Ethics Committee in China-Japan Friendship Hospital.

Animal grouping and model establishment

All rats were randomized into 3 groups: sham operation group $(n=30)$, MOF group $(n=30)$, and the CBP group ( $n=30)$. MOF in rats were established by surgical trauma, hemorrhagic shock and reperfusion as the first hit and the endotoxin injection as the second hit. Rats were first intraperitoneally anesthetized with thiopental sodium (Sigma-Aldrich Chemical Company, St Louis MO, USA) at a dosage of $85 \mathrm{mg} / \mathrm{kg}$ according 


\section{Kidney Blood Pressure Research}

Kidney Blood Press Res 2018;43:938-950

\begin{tabular}{l|l}
\hline DOI: $10.1159 / 000490473$ & (C) 2018 The Author(s). Published by S. Karger AG, Basel
\end{tabular}

Publisned online: 12 June, 2018

www.karger.com/kbr

Ling et al:: Effects of CBP on MOF in Rats

to the body weight, then fixed and sterilized. Afterwards, common carotid artery, femoral artery, and femoral vein were separated and intubated respectively with the common carotid artery being connected to a digital PowerLab data acquisition system (PowerLab 8/30, AD Instruments, Castle Hill, Australia). Ten min after the surgery, mean arterial pressure (MAP) was reduced to $35 \sim 40 \mathrm{mmHg}$ within $5 \mathrm{~min}$ and maintained for $1 \mathrm{~h}$ by withdrawing blood from the femoral artery, and the hemorrhagic shock was induced. Then, MAP of the rat was restored to over $80 \%$ of the preoperative value by intravenously reinfusing with $60 \%$ lost blood and equilibrium liquid twice the volume of lost blood. After a recovery of $12 \mathrm{~h}$, the rat was anesthetized with inhaled ethyl ether. Then Salmonella abortus equi endotoxin (Sigma-Aldrich Chemical Company, St Louis MO, USA) was injected at a dosage of $4.5 \mathrm{mg} / \mathrm{Kg}$ via femoral vein within $15 \mathrm{~min}$. In the sham operation group, rats were only treated with surgical trauma.

\section{CBP treatment}

A Braun Dipact CRRT machine with an F60 channel and filter (B. Braun Melsungen AG, Melsungen, Germany) was applied on rats in the CBP group to give a CBP treatment $24 \mathrm{~h}$ after endotoxin injection. A two-way indwelling catheter was inserted through the right internal jugular vein to form an extracorporeal circulation system. Substitution fluid was infused at a flow rate of $200 \mathrm{~mL} / \mathrm{min}$ with dilution method. Before connected with the catheter, the right internal jugular vein was circularly washed with heparin-saline solution (5000 U/L) for $30 \mathrm{~min}$, and heparin of $1500 \mathrm{U} / \mathrm{h}$ was used for continuous anticoagulation during the treatment. The duration of CBP treatment lasted for $24 \mathrm{~h}$ to cover the whole experiments.

\section{Measurements of the parameters related to MOF}

Then $1 \mathrm{~mL}$ of peripheral blood were collected from saphenous vein of each rat and tested at 5 time points including $\mathrm{T}_{0}$ (before withdrawing blood from rats), $\mathrm{T}_{1}\left(24 \mathrm{~h}\right.$ after endotoxin injection), $\mathrm{T}_{2}(6 \mathrm{~h}$ after CBP), $\mathrm{T}_{3}\left(12 \mathrm{~h}\right.$ after CBP), and $\mathrm{T}_{4}(24 \mathrm{~h}$ after CBP). After $1 \mathrm{~h}$ of standing, the blood samples were centrifugated at $3000 \mathrm{rpm}$ for $10 \mathrm{~min}$. Collected supernatant was then preserved at $-80^{\circ} \mathrm{C}$ for further use. Levels of serum glutamate pyruvate transaminase (SGPT), serum glutamate oxaloacetate transaminase (SGOT), creatinine $(\mathrm{Cr})$, blood urea nitrogen (BUN), and arterial oxygen partial pressure $\left(\mathrm{PaO}_{2}\right)$ of each blood sample were determined with an automatic biochemical analyzer (Olympus AU5400, Tokyo, Japan). According to the diagnostic index of MOF [23], rats with 2 or more than 2 organ failures $24 \mathrm{~h}$ after hits were considered as MOF rats. Otherwise, rats that died or exhibited MOF within $24 \mathrm{~h}$ after hits were considered as failed cases of hemorrhagic shock resuscitation (included in the total number). Diagnostic indexes of MOF were described as follows: respiratory failure: $\mathrm{PaO}_{2}<8 \mathrm{kPa}(60 \mathrm{mmHg}$ ); liver failure: SGOT/SGPT > two times the control value; kidney failure: $\mathrm{Cr} / \mathrm{BUN}>$ two times the control value; gastrointestinal failure: gastrointestinal tract showed mucosal bleeding, erosion and stress ulceration. Six rats in each group at each measuring time from $\mathrm{T}_{0}$ to $\mathrm{T}_{4}$, was euthanized and liver, kidney, as well as lung tissues, were collected. Then part of the tissues were cut and fixed in formalin (Sigma-Aldrich Chemical Company, St Louis MO, USA), and the rest were preserved in liquid nitrogen at $-80^{\circ} \mathrm{C}$.

\section{Reverse-transcription quantitative polymerase chain reaction (RT-qPCR)}

Total RNA from liver, kidney, and lung tissues were extracted using a RNeasy mini kit (Qiagen, $\mathrm{GmbH}$, Hilden, Germany). Total RNA was regarded as a template for reverse transcription reaction using the TaqMan ${ }^{\circledR}$ MicroRNA Reverse Transcription kit (Applied Biosystems Inc., Foster City, CA, USA) with a total reaction volume of $15 \mu \mathrm{L}$ under the following reaction condition: having been incubated for $30 \mathrm{~min}$ at $16^{\circ} \mathrm{C}$, the reaction system was then heated at $42^{\circ} \mathrm{C}$ for $30 \mathrm{~min}$, followed by 5 -min incubation at $85^{\circ} \mathrm{C}$. The qRT-PCR was performed using TaqMan Universal PCR kit (Applied Biosystems Inc., Foster City, CA, USA) with the following reaction condition: having been initiated for $10 \mathrm{~min}$ at $95^{\circ} \mathrm{C}$, the reaction system was performed with 40 cycles of denaturation for $30 \mathrm{~s}$ at $95^{\circ} \mathrm{C}$ and 1 -min annealing at $60^{\circ} \mathrm{C}$. Afterwards, RTPCR was conducted by using ABI 7500 Real-Time PCR System (Applied Biosystems Inc., Foster City, CA, USA). Glyceraldehyde-3-phosphate dehydrogenase (GAPDH) was applied as an internal reference. We have exhibited the primers used in this experiment in Table 1 . The relative expressions were calculated using the $2^{-\Delta \Delta \mathrm{Ct}}$ method. 


\section{Kidney Blood Pressure Research}

Kidney Blood Press Res 2018;43:938-950

\begin{tabular}{l|l}
\hline DOI: 10.1159/000490473 & (C) 2018 The Author(s). Published by S. Karger AG, Basel
\end{tabular}

Publishned online: 12 June, 2018

www.karger.com/kbr

Ling et al.: Effects of CBP on MOF in Rats
Western blot analysis

After being washed by phosphate-

buffered saline (PBS), the tissues were ground into homogenate. Cell lysate containing protease inhibitor was supplemented into tissue homogenate, followed by shaking the mixture at $4{ }^{\circ} \mathrm{C}$ for $5 \mathrm{~min}$. After 10-min centrifugation at $14,400 \mathrm{rpm}$, the supernatant was collected. The protein was extracted using the Qproteome Mammalian Protein Prer kit (Qiagen, GmbH, Hilden, Germany). After protein concentration having been measured and adjusted, $6 \times$ loading buffer was added, and then samples were heated up to $100^{\circ} \mathrm{C}$ and preserved in liquid nitrogen at $-20^{\circ} \mathrm{C}$.
Table 1. Primer sequences for RT-qPCR. Note: RT-qPCR: reverse-transcription quantitative polymerase chain reaction; MAPK, mitogen-activated protein kinase; iNOS, inducible nitric oxide synthase; GAPDH, glyceraldehyde-3-phosphate dehydrogenase; F, forward; R, reverse

\begin{tabular}{lc}
\hline Gene & \multicolumn{1}{c}{ Sequence } \\
\hline p38 MAPK & F: 5'-TAGACGAATGGAAGAGCCTGA-3' \\
& R: 5'-GGCACTTGAATGGTATTTGGAGA-3' \\
iNOS & F: 5'-CAGCTGGGCTGTACAAACCTT-3' \\
& R: 5'-CATTGGAAGTGAAGCGTTTCG-3' \\
GAPDH & F: 5'-ACCACAGTCCATGCCATCAC-3' \\
& R: 5'-TCCACCACCCTGTTGCTGTA-3' \\
\hline
\end{tabular}

$50 \mu \mathrm{g}$ of protein sample was loaded onto sodium dodecyl sulphate-polyacrylamide gel electrophoresis (SDS-PAGE). The proten was separated and transferred onto a nitrocellulose membrane by siphonage. The membranes were blocked with skim milk and then cultured with primary antibodies (p-p38 MAPK or p38 MAPK, 1:1000 dilution, mouse antihuman monoclonal antibodies) overnight at $4^{\circ} \mathrm{C}$. The membranes were washed 4 times with Tris-buffered saline tween-20 (TBST) (each time for $10 \mathrm{~min}$ ), and then incubated with diluted IRDye ${ }^{\mathrm{TM}}$ 800DX-conjugated goat anti-mouse immunoglobulin G (IgG, 1: 10, 000) for $1 \mathrm{~h}$ at room temperature. The protein bands were developed after washed by TBST for 4 times. GAPDH was conducted as an internal reference. Antibodies used in this experiment were all purchased from Santa Cruz Biotechnology, Inc. (Santa Cruz, CA, USA). The intensity of protein band was determined quantitatively by LabWorks Image Acquisition and Analysis Software (UVP, Inc., Upland, CA, USA) to analyze the protein concentrations of p-p38 MAPK, p38 MAPK, and GAPDH.

\section{Determination of serum nitric oxide levels}

Serum nitric oxide levels in each sample were determined using nitrate reductase assay and Nitric Oxide Assay Kit (Shanghai Honsun Biological Technology Co., Ltd., Shanghai, China) at each measuring time point. An amount of $50 \mu \mathrm{L}$ serum with $400 \mu \mathrm{L}$ lysis buffer was incubated in water bath of $37^{\circ} \mathrm{C}$ for $1 \mathrm{~h}$, and then $500 \mu \mathrm{L}$ buffer was supplemented for $40 \mathrm{~min}$ standing at room temperature. The mixture was centrifuged for $10 \mathrm{~min}$ at 3500 4000 r/min. Collected supernatant was supplemented with chromogenic reagents for $10 \mathrm{~min}$. The OD value of each sample was determined by a microplate reader (Thermo Fisher Scientific, Waltham, MA, USA) at $550 \mathrm{~nm}$. On the basis of the standard curves with the OD values of the samples, serum nitric oxide levels were calculated and recorded.

\section{Enzyme-linked immunosorbent assay (ELISA)}

Serum level of TNF-T was detected in accordance with the instructions of ELISA kit (ml002859, Shanghai Enzyme-linked Biotechnology Co., Ltd., Shanghai, China). A total of $100 \mu \mathrm{L}$ from each standard fluid or sample was added to each well in duplicate, and $50 \mu \mathrm{L}$ of the sample diluent was added to each well. Then $50 \mu \mathrm{L}$ of the biotinylated antibody reagent was added to each well and incubated for $1 \mathrm{~h}$ at room temperature, at $20 \sim 25^{\circ} \mathrm{C}$. Plates were then washed 4 times with a washing solution. Then, $100 \mu \mathrm{L}$ of TMB substrate solution was added and incubated in the dark for $10 \mathrm{~min}$ at room temperature. Subsequently, 100 $\mu \mathrm{L}$ of stop solution was added to each well to stop the reaction. Absorbance was measured on an automated ELISA plate reader (Dynex, DSX, Chantily, USA) set at the wavelength of $450 \mathrm{~nm}$. The standard curve was generated by plotting the average absorbance obtained for each standard concentration on the vertical (Y) axis $v s$. the corresponding TNF- $\alpha$ level on the horizontal (X) axis. The amount of TNF- $\alpha$ in each sample was determined with this curve as $\mathrm{pg} / \mu \mathrm{L}$. 


\section{Kidney Blood Pressure Research}

\begin{tabular}{|c|c|}
\hline $\begin{array}{l}\text { DOI: 10.1159/000490473 } \\
\text { Publisned online: } 12 \text { June, } 2018\end{array}$ & $\begin{array}{l}\text { (c) } 2018 \text { The Author(s). Published by S. Karger AG, Basel } \\
\text { www.karger.com/kbr }\end{array}$ \\
\hline
\end{tabular}

Ling et al.: Effects of CBP on MOF in Rats

\section{Hematoxylin-eosin (HE) staining}

Fresh tissues were extracted and placed in 4\% formalin overnight. On the following day, the tissues were dehydrated and embedded in paraffin. Then tissues were sliced into sections at a thickness of 4 um, followed by the staining with HE, observation and photograph under a fluorescence microscope. The detailed procedures were as follows: glass slide was dewaxed in xylene I and II and then in alcohol $(100 \%$, $90 \%$ and $70 \%$ ), and washed with tap water for $2 \sim 3 \mathrm{~min}$. After 5-min staining in hematoxylin, glass slide was washed again for 5 10 min. Next, glass slide was immersed in 1\% hydrochloric acid for $5 \sim 10 \mathrm{~s}$ for color separation and then treated with 2-min washing with tap water, 2 min each time. Afterwards, glass slide was stained with eosin and incubated for 1 2 min, and washed with tap water for 1 2 s. After section, tissues were dehydrated with alcohol (80\%, 90\% and 100\%) for 30 s. Finally, the sections were immersed in xylene I and II for 5 min and sealed with neutral balsam.

\section{Statistical analysis}

SPSS 19.0 software was applied for statistical analysis in this study. Data were expressed as mean \pm standard deviation. Comparison of data between two groups was performed with $t$-test. Comparisons among multiple groups were assessed by mixed-design ANOVA. Pairwise comparison of data among groups was processed with LSD- $t$ test. $P<0.05$ was considered to be statistically significant.

\section{Results}

CBP treatment lowers the levels of SGPT, SGOT, Cr, and BUN in MOF rats

Initially, to manifest the effects of CBP treatment on organ functions related to MOF, we detected the levels of SGPT, SGOT, $\mathrm{Cr}, \mathrm{BUN}$ and $\mathrm{PaO}_{2}$ in all testing groups at each measuring time point, the results of which are shown in Table 2. Level of each parameter in the sham operation group remained almost unchanged at each time point (all $p>0.05$ ). And no differences were observed among 3 groups at $\mathrm{T}_{0}$ (all $p>0.05$ ). However, the levels of SGPT, SGOT, Cr, and BUN in the MOF and CBP groups were increased at $\mathrm{T}_{1}, \mathrm{~T}_{2}, \mathrm{~T}_{3}$ and $\mathrm{T}_{4}$ than those in the sham operation group and at $\mathrm{T}_{0}$, while the $\mathrm{PaO}_{2}$ level was decreased (all $p<0.05$ ) after the MOF model was established. Besides, the levels of SGPT, SGOT, Cr, and BUN in the MOF group were continually elevated at $\mathrm{T}_{2}, \mathrm{~T}_{3}$, and $\mathrm{T}_{4}$ whereas the level of $\mathrm{PaO}_{2}$ value was significantly reduced (all $p<0.05$ ). By contrast, the levels of SGPT, SGOT, $\mathrm{Cr}$, and BUN in the CBP group were persistently declined at $\mathrm{T}_{2}, \mathrm{~T}_{3}$, and $\mathrm{T}_{4}$, with a significant increase of $\mathrm{PaO}_{2}$ level (all $p<0.05$ ). Moreover, no distinct differences indicated in each parameter between the

Table 2. CBP treatment decreases the levels of SGPT, SGOT, Cr, and BUN in MOF rats. Note: SGPT, serum glutamate pyruvate transaminase; SGOT, serum glutamate oxaloacetate transaminase; Cr, creatinine; BUN, blood urea nitrogen; $\mathrm{T}_{0}$, before withdrawing blood from rats in the CBP group; $\mathrm{T}_{1} 24 \mathrm{~h}$ after endotoxin injection; $\mathrm{T}_{2}, 6 \mathrm{~h}$ after CBP; $\mathrm{T}_{3}, 12 \mathrm{~h}$ after CBP; $\mathrm{T}_{4}, 24 \mathrm{~h}$ after CBP; ${ }^{a}$, vs. the sham operation group, $\mathrm{p}<0.05$; ${ }^{\mathrm{b}}$, vs. the MOF group, $\mathrm{p}<0.05$; $^{\mathrm{c}}$, vs. the same group at $\mathrm{T}_{0}, \mathrm{p}<0.05$; $^{\mathrm{d}}$, vs. the same group at $\mathrm{T}_{1}, \mathrm{p}<0.05$; ${ }^{\mathrm{e}}$, vs. the same group at $\mathrm{T}_{2}, \mathrm{p}<0.05$; ${ }^{\mathrm{f}}$, vs. the same group at $\mathrm{T}_{3}, \mathrm{p}<0.05$; each group includes 6 rats; data were analyzed by mixed-design ANOVA

\begin{tabular}{|c|c|c|c|c|c|c|}
\hline Time point & Group & SGPT (u/L) & SGOT (u/L) & $\mathrm{Cr}$ (umol/L) & BUN (mmol/L) & $\mathrm{PaO}_{2}(\mathrm{kPa})$ \\
\hline \multirow{4}{*}{$\mathrm{T}_{0}$} & Sham operation group & $37.29 \pm 8.65$ & $54.61 \pm 12.13$ & $15.35 \pm 0.82$ & $4.39 \pm 0.21$ & $14.16 \pm 0.23$ \\
\hline & MOF group & $35.19 \pm 3.25$ & $55.43 \pm 11.18$ & $14.81 \pm 1.40$ & $4.19 \pm 0.53$ & $13.53 \pm 0.35$ \\
\hline & CBP group & $35.49 \pm 4.45$ & $54.53 \pm 5.38$ & $13.23 \pm 1.97$ & $4.50 \pm 0.31$ & $14.01 \pm 0.67$ \\
\hline & Sham operation group & $37.65 \pm 6.10$ & $53.78 \pm 14.40$ & $14.42 \pm 1.22$ & $4.31 \pm 0.62$ & $13.85 \pm 0.59$ \\
\hline \multirow[t]{3}{*}{$\mathrm{T}_{1}$} & MOF group & $154.06 \pm 14.84 \mathrm{ac}$ & $181.60 \pm 12.27^{a c}$ & $26.96 \pm 2.30^{\mathrm{ac}}$ & $7.49 \pm 1.06^{\mathrm{ac}}$ & $14.48 \pm 1.62^{\mathrm{ac}}$ \\
\hline & CBP group & $148.48 \pm 26.74^{a c}$ & $198.57 \pm 13.06^{a c}$ & $26.94 \pm 2.09 \mathrm{ac}$ & $7.55 \pm 1.18^{\mathrm{ac}}$ & $14.48 \pm 0.15^{\mathrm{ac}}$ \\
\hline & Sham operation group & $37.30 \pm 9.22$ & $56.49 \pm 6.62$ & $14.45 \pm 1.23$ & $4.35 \pm 0.21$ & $14.00 \pm 1.08$ \\
\hline \multirow[t]{3}{*}{$\mathrm{T}_{2}$} & MOF group & $218.26 \pm 21.61$ acd & $390.13 \pm 32.61$ acd & $30.53 \pm 3.96$ acd & $8.10 \pm 1.61 \mathrm{acd}$ & $12.28 \pm 0.30$ acd \\
\hline & $\mathrm{CBP}$ group & $128.77 \pm 15.56^{\mathrm{abcd}}$ & $158.62 \pm 19.30^{\mathrm{abcd}}$ & $23.16 \pm 1.71$ abcd & $5.61 \pm 0.84^{\text {abcde }}$ & $14.97 \pm 0.32^{\mathrm{abcd}}$ \\
\hline & Sham operation group & $37.18 \pm 2.43$ & $55.01 \pm 11.58$ & $15.28 \pm 0.78$ & $4.31 \pm 0.47$ & $13.89 \pm 0.65$ \\
\hline \multirow[t]{3}{*}{$\mathrm{T}_{3}$} & MOF group & $352.09 \pm 15.43^{\text {acde }}$ & $628.74 \pm 54.12$ acde & $34.79 \pm 2.50^{\text {acde }}$ & $9.83 \pm 0.78_{\text {acde }}$ & $11.52 \pm 0.37^{\text {acde }}$ \\
\hline & CBP group & $116.55 \pm 5.67$ abcde & $129.95 \pm 10.26$ abcde & $20.67 \pm 0.84$ abcde & $3.11 \pm 0.26$ abcde & $15.96 \pm 0.43^{\text {abcd }}$ \\
\hline & Sham operation group & $36.77 \pm 9.68$ & $55.39 \pm 12.25$ & $14.61 \pm 2.32$ & $4.43 \pm 0.34$ & $13.81 \pm 0.68$ \\
\hline \multirow[t]{2}{*}{$\mathrm{T}_{4}$} & MOF group & $564.98 \pm 42.24^{\text {acdef }}$ & $819.95 \pm 53.85$ acdef & $37.76 \pm 2.74^{\text {acdef }}$ & $10.83 \pm 0.64$ acdef & $10.20 \pm 0.41^{\text {acde }}$ \\
\hline & CBP group & $36.74 \pm 18.48^{\text {bcdef }}$ & $54.41 \pm 2.46$ bcdef & $15.57 \pm 1.65$ bcdef & $4.68 \pm 0.14$ bcdef & $13.93 \pm 0.61 \mathrm{bcde}$ \\
\hline
\end{tabular}




\section{Kidney Blood Pressure Research}

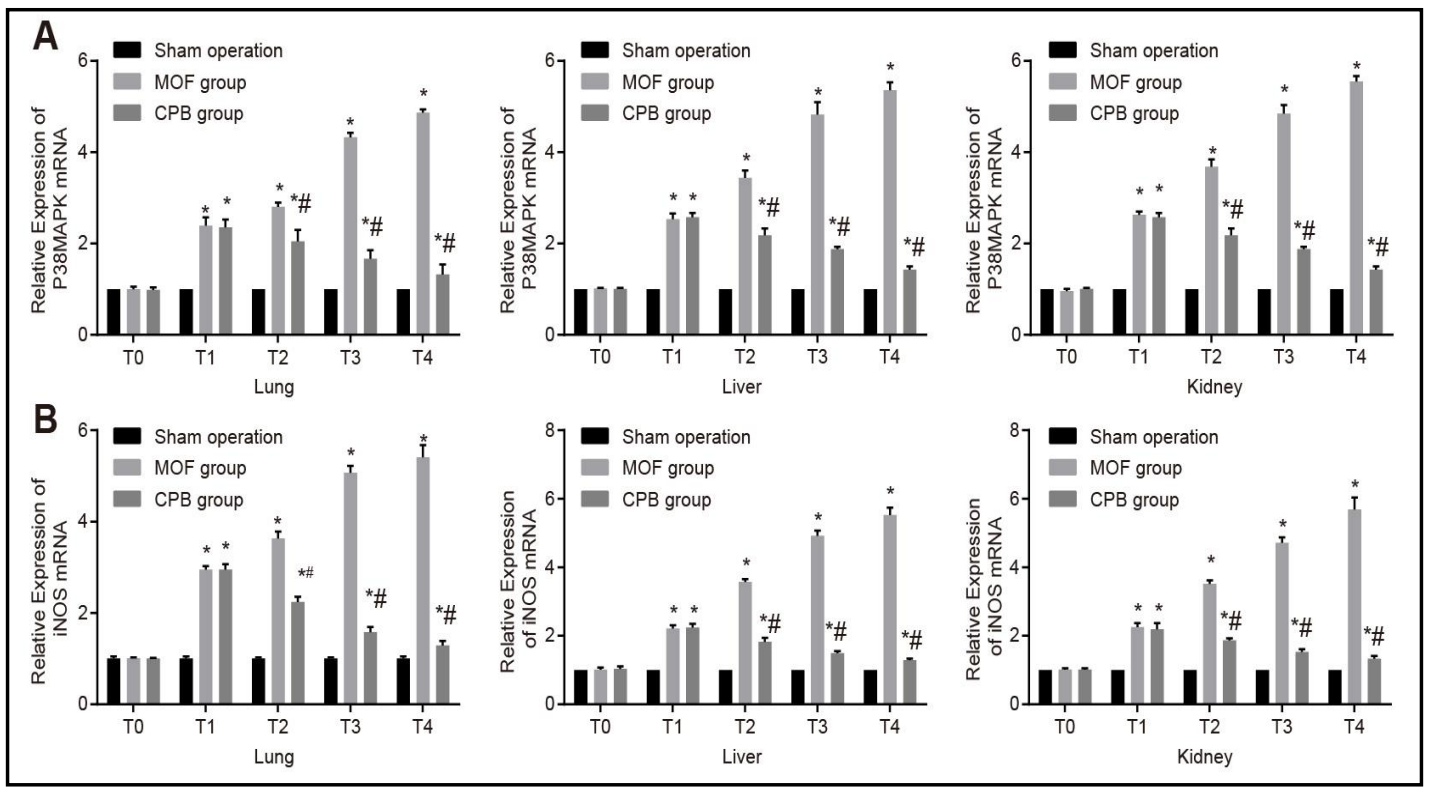

Fig. 1. RT-qPCR demonstrates that CBP treatment down-regulates the mRNA expressions of iNOS and p38 MAPK in MOF rats. Panel A, relative mRNA expressions of p38 MAPK; Panel B, relative mRNA expressions of iNOS; MKPK, mitogen-activated protein kinase; iNOS, inducible nitric oxide synthase; RT-qPCR, reversetranscription quantitative polymerase chain reaction; $\mathrm{T}_{0}$, before hemorrhage in the CBP and MOF group; $\mathrm{T}_{1}$, $24 \mathrm{~h}$ after endotoxin injection; $\mathrm{T}_{2}, 6 \mathrm{~h}$ after CBP treatment; $\mathrm{T}_{3}, 12 \mathrm{~h}$ after CBP treatment; $\mathrm{T}_{4}, 24 \mathrm{~h}$ after CBP treatment; ", vs. the sham operation group, p<0.05; \#, vs. the MOF group, $\mathrm{p}<0.05$; each group includes 6 rats; pairwise comparison of data among groups was processed with mixed-design ANOVA.

CBP and sham operation groups $24 \mathrm{~h}$ after CBP treatment $\left(\mathrm{T}_{4}\right)$ (all $p>0.05$ ). These findings demonstrated that CBP treatment may exert protective role in organ functions in MOF rats.

CBP treatment down-regulates the mRNA expressions of iNOS and p38 MAPK in MOF rats

Subsequently, relative mRNA expressions of iNOS and p38 MAPK in liver, kidney, and lung tissues at each time point were determined by RT-qPCR in order to identify the effects of CBP treatment on the p38MAPK signaling pathway. As shown in Fig. 1, there were no remarkable differences shown in mRNA expressions of iNOS and p38 MAPK in the sham operation group at all testing time points (all $p>0.05$ ). And no significant differences were showed in mRNA expressions of iNOS and p38 MAPK among 3 testing groups at $\mathrm{T}_{0}$ (all $p>0.05$ ). However, in contrast to the sham operation group, the mRNA expressions of iNOS and p38 MAPK in the MOF and CBP groups were markedly enhanced at $\mathrm{T}_{1}, \mathrm{~T}_{2}, \mathrm{~T}_{3}$, and $\mathrm{T}_{4}$ (all $p<0.05$ ) after the MOF model was established. Besides, mRNA expressions of iNOS and p38 MAPK in the MOF group were continually elevated at $\mathrm{T}_{2}, \mathrm{~T}_{3}$, and $\mathrm{T}_{4}$, with a significant augment compared to the sham operation group (all $p<0.05$ ). While in the CBP group, mRNA expressions of iNOS and p38 MAPK were persistently declined at $\mathrm{T}_{2}, \mathrm{~T}_{3}$, and $\mathrm{T}_{4}$ after CBP treatment. In the CBP group, the mRNA expressions of iNOS and p38 MAPK after CBP treatment were still elevated compared with those in the sham operation group, but markedly decreased than those in the MOF group (all $p<0.05$ ). The above results showed that CBP treatment may inactivate the p38 MAPK signaling pathway in MOF rats.

\section{CBP treatment declines the protein levels of p-p38 MAPK and p38 MAPK in MOF rats}

Next, we performed western blot analysis to detect the influence of CBP treatment on the protein levels of p-p38 MAPK and p38 MAPK in liver, kidney, and lung tissues at each time point, the results of which are shown in Fig. 2. In the sham operation group at all testing time points, there were no significant differences in protein levels of p-p38 MAPK and p38 MAPK 


\section{Kidney Blood Pressure Research}

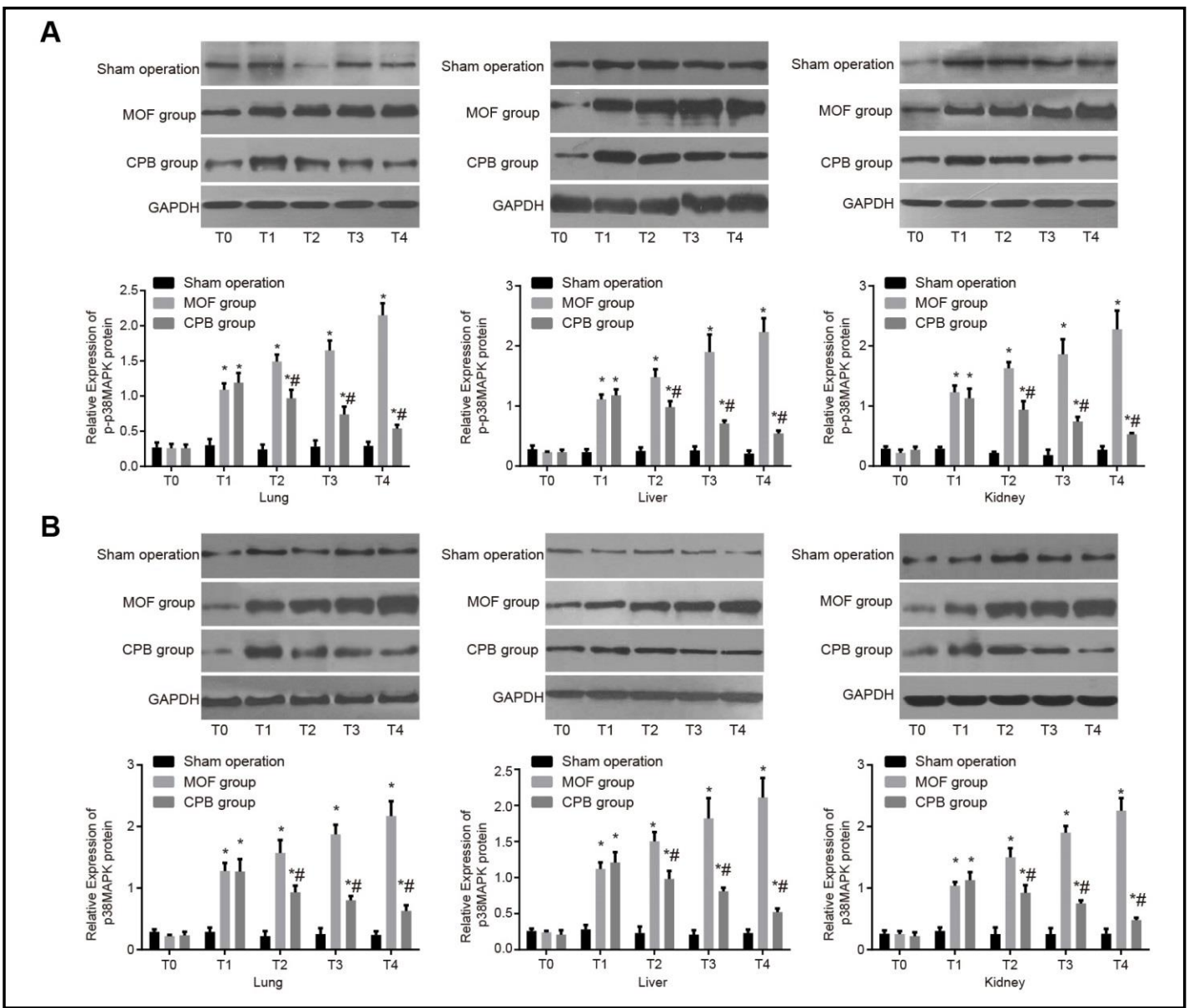

Fig. 2. Western blot analysis manifests that CBP treatment down-regulates the protein levels of p-p38 MAPK and p38 MAPK in MOF rats. Panel A, protein levels of p-p38 MAPK; Panel B, protein levels of p38 MAPK; p-p38 MAPK, phosphorylated p38 mitogen-activated protein kinase; $\mathrm{T}_{0}$, before hemorrhage in the CBP and MOF group; $\mathrm{T}_{1} 24 \mathrm{~h}$ after endotoxin injection; $\mathrm{T}_{2}, 6 \mathrm{~h}$ after CBP treatment; $\mathrm{T}_{3}, 12 \mathrm{~h}$ after CBP treatment; $\mathrm{T}_{4}$,

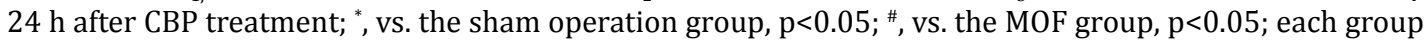
includes 6 rats; pairwise comparison of data among groups was processed with mixed-design ANOVA.

(all $p>0.05$ ). Among 3 testing groups at $\mathrm{T}_{0}$, no marked differences were exhibited in protein levels of p-p38 MAPK and p38 MAPK (all $p>0.05$ ). However, in comparison with the sham operation group, protein levels of p-p38 MAPK and p38 MAPK in the MOF and CBP groups were markedly increased at $\mathrm{T}_{1}, \mathrm{~T}_{2}, \mathrm{~T}_{3}$, and $\mathrm{T}_{4}$ (all $p<0.05$ ) after MOF model establishment. Besides, protein levels of p-p38 MAPK and p38 MAPK in the MOF group were continually elevated at $\mathrm{T}_{2}, \mathrm{~T}_{3}$, and $\mathrm{T}_{4}$, which was evidently enhanced than those in the sham operation group (all $p<0.05$ ). By contrast, protein levels of p-p38 MAPK and p38 MAPK in the CBP group were continuously declined at $\mathrm{T}_{2}, \mathrm{~T}_{3}$, and $\mathrm{T}_{4}$ after CBP treatment. The expressions of p38 MAPK and iNOS in CBP group after treatment were still elevated compared with those in the sham operation group, but markedly decreased compared with those in the MOF group (all $p<0.05$ ). It can be concluded that CBP treatment might prevent the p38MAPK signaling pathway from activation in MOF rats.

\section{CBP treatment reduces serum levels of nitric oxide and TNF- $\alpha$ in MOF rats}

In the following experiment, ELISA was conducted to evaluate the effects of CBP treatment on serum levels TNF- $\alpha$ in all testing groups at each time point and the content of nitric oxide was determined by nitric oxide assay kit. No marked differences were observed 


\section{Kidney Blood Pressure Research}

in serum levels of nitric oxide and TNF- $\alpha$ in 3 testing groups before hemorrhage $\left(\mathrm{T}_{0}\right)$ (all $p>$ $0.05)$. And there were no remarkable differences in serum levels of nitric oxide and TNF- $\alpha$ in the sham operation group among all testing time points (all $p>0.05$ ). Compared with the sham operation group, serum levels of nitric oxide and TNF- $\alpha$ in the MOF and CBP groups were markedly elevated at $\mathrm{T}_{1}, \mathrm{~T}_{2}, \mathrm{~T}_{3}$, and $\mathrm{T}_{4}$ (all $p<0.05$ ) after the establishment of MOF model. Besides, serum levels of nitric oxide and TNF- $\alpha$ in the MOF group were continually elevated at $\mathrm{T}_{2}, \mathrm{~T}_{3}$, and $\mathrm{T}_{4}$, which were remarkably increased than those in the sham operation group (all $p<0.05$ ). However, In the CBP group, serum levels of nitric oxide and TNF- a in the CBP group were persistently declined at $\mathrm{T}_{2}, \mathrm{~T}_{3}$, and $\mathrm{T}_{4}$ after CBP treatment. The serum levels of nitric oxide and TNF- $\alpha$ in the CBP group after treatment were still facilitated compared with those in the sham operation group, but markedly lower than those in the MOF group (all $p<0.05$ ) (Fig. 3). In that case, we can conclude that CBP treatment may decrease the serum levels of nitric oxide and TNF- $\alpha$ in MOF rats.

\section{Histological analysis of liver, kidney, and lung tissues during CBP treatment}

In the following experiment, in order to determine the effects of CBP treatment on the histological changes of liver, kidney, and lung tissues in MOF rats, we adapted HE staining. No marked differences showed in each tissue among 3 testing groups at $\mathrm{T}_{0}$. And in the sham operation group, each tissue showed no obvious differences among all testing time points. Nevertheless, tissue histopathological changes of different degrees were observed in the MOF and CBP group after the MOF model was established in liver, kidney, and lung of rats. Swelling and deformation of renal tubular epithelial cells, as well as cell detachment and thrombus deposition could be observed in rats in the MOF and CBP groups. As for the liver tissues in rats in the MOF and CBP groups, central vein of liver indicated narrowing, congestion, and swelling, associated with ballooning degeneration or other degenerative changes in hepatocytes. Besides, lung tissues in rats with MOF exhibited edema, swelling, alveolous atrophy, and inflammatory cell infiltration. However, these symptoms mentioned above were all gradually relieved after CBP treatment, and the tissues in the CBP group gradually returned to normal status $24 \mathrm{~h}$ after the treatment $\left(\mathrm{T}_{4}\right)$ (Fig. 4). We can reach a conclusion that CBP treatment could relieve the symptoms of MOF.

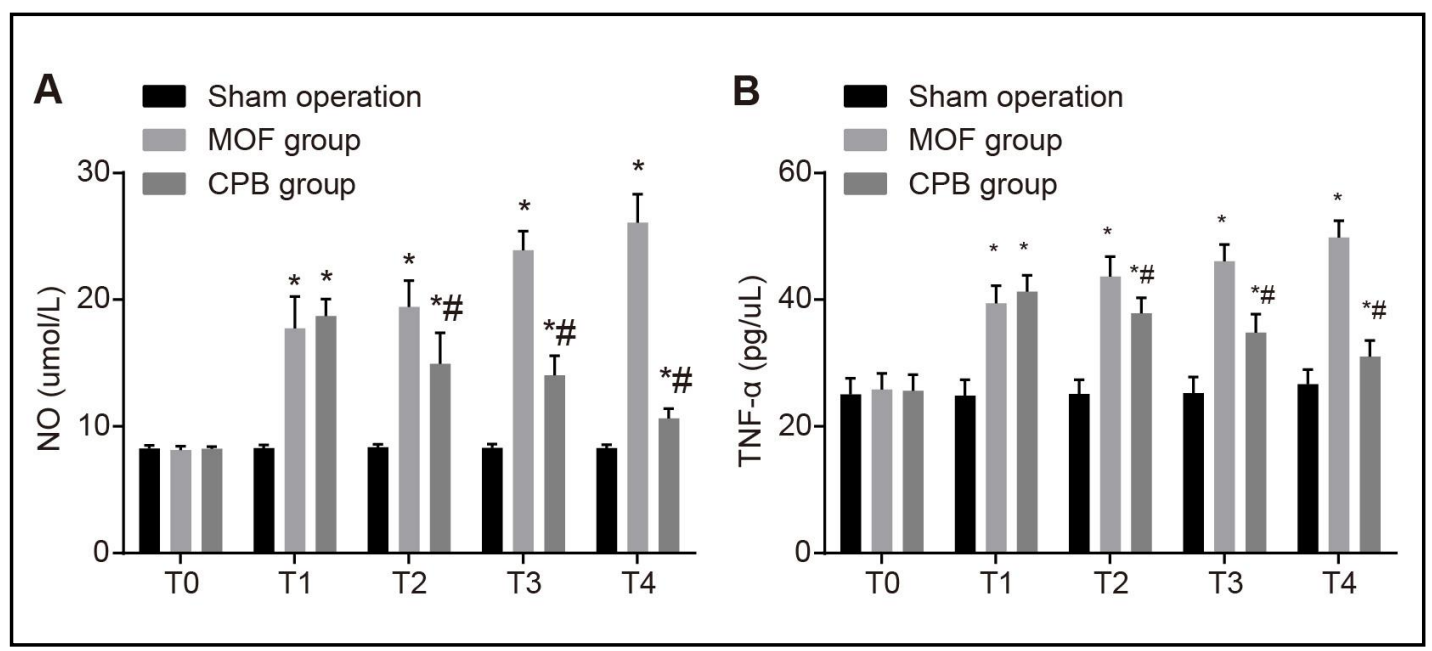

Fig. 3. CBP treatment decreases serum levels of nitric oxide and TNF- $\alpha$ in MOF rats. Panel A, serum level of nitric oxide; Panel B, serum level of TNF- $\alpha$; T, before hemorrhage in the MOF and CBP group; $\mathrm{T}_{1}, 24 \mathrm{~h}$ after endotoxin injection; $\mathrm{T}_{2}, 6 \mathrm{~h}$ after CBP treatment; $\mathrm{T}_{3}, 12 \mathrm{~h}$ after CBP treatment; $\mathrm{T}_{4}, 24 \mathrm{~h}$ after CBP treatment; ", vs. the sham operation group, $\mathrm{p}<0.05$; \#, vs. the MOF group, $\mathrm{p}<0.05$; NO, nitric oxide; each group includes 6 rats; pairwise comparison of data among groups was processed with mixed-design ANOVA. 


\section{Kidney Blood Pressure Research}

Discussion

MOF, known as a severe syndrome with no effective pharmacologic therapy, has been a major health burden worldwide and an outstanding pathogenesis of morbidity and mortality among critically ill patients [24]. Fortunately, CBP treatment has shown significant therapeutic effect in ameliorating the prognosis of MOF, but the exact mechanisms are still unclear [16]. We aimed to explore novel treatments for MOF by investigating the modulatory effects of CBP on ameliorating MOF via p38 MAPK signaling pathway in a rat model. Identification of the potential function of the p38 MAPK signaling pathway in MOF may shed lights on the novel therapeutic strategies for MOF and the functional repair of tissue injury.

MOF model in rats was established through 2 steps, with hemorrhagic shock as the first hit and endotoxemia as the second hit Levels of SGPT, SGOT, Cr, BUN, and $\mathrm{PaO}_{2}$ value were chosen to evaluate the progress of MOF in liver, kidney, and lung tissues. The results revealed that the levels of SGPT, SGOT, $\mathrm{Cr}$, and BUN in the CBP group after treatment were significantly declined compared with those in the MOF group, while that the $\mathrm{PaO}_{2}$ value was increased, indicating

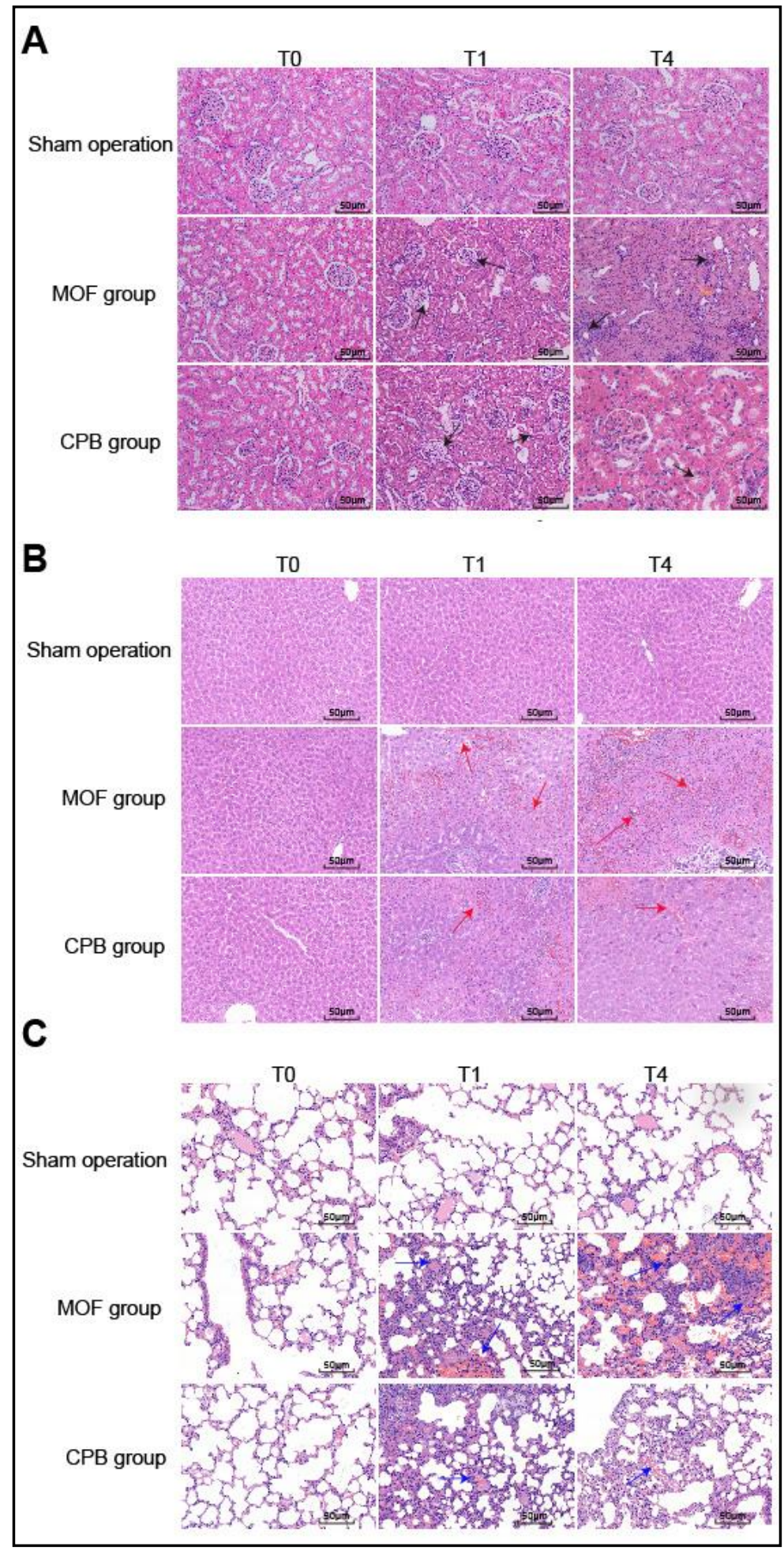

Fig. 4. CBP treatment affects the pathological changes of kidney, liver and lung in rats. Panel A, images of rat liver $(200 \times)$; Panel B, images of rat kidney $(200 \times)$; Panel C, images of rat lung $(200 \times)$; HE, hematoxylin and eosin; $\mathrm{T}_{0}$, before hemorrhage in the CBP and MOF group; $\mathrm{T}_{1}, 24 \mathrm{~h}$ after endotoxin injection; $\mathrm{T}_{2}, 6 \mathrm{~h}$ after CBP treatment; $\mathrm{T}_{3}, 12 \mathrm{~h}$ after CBP treatment; $\mathrm{T}_{4}, 24 \mathrm{~h}$ after CBP treatment. 


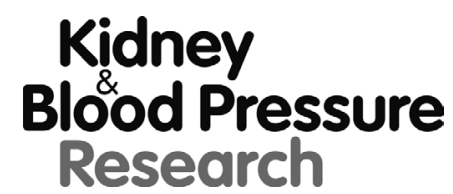

\begin{tabular}{l|l}
\hline Kidney Blood Press Res 2018;43:938-950 \\
\hline \begin{tabular}{l|l} 
DOI: 10.1159/000490473 & (c) 2018 The Author(s). Published by S. Karger AG, Basel \\
Publisned onlIne: I2 June, 2018 & ww.karger.com/kbr
\end{tabular} \\
\hline
\end{tabular}

Ling et al.: Effects of CBP on MOF in Rats

that damage caused by MOF was greatly alleviated by CBP treatment. In addition, results of HE staining also confirmed that the swelling and inflammatory infiltration of liver, kidney, and lung tissues in the CBP group was gradually relieved after treatment. A former study has proved that CBP could ameliorate the prognosis of patients suffering from MOF via unknown mechanisms, which was in accordance with our results [16]. CBP can not only improve the general conditions but also effectively improve gut barrier dysfunction, whose beneficial effect on gut barrier dysfunction is associated with the improvement of cytoskeletal instability, by down-regulating iNOS through the removal of excess proinflammatory factors [25]. Another data showed that after CBP treatment, endothelial hyperpermeability induced by serum from severe acute pancreatitis (SAP) patients with lung injury was ameliorated [26]. Moreover, CBP treatment could improve myocardial function, shorten the oliguria period, decrease the fatality rate, and improve the prognosis of cardiorenal syndrome (CRS) patients [27].

p38 MAPK signaling pathway was a prominent factor on regulating cell apoptosis, immune, and inflammatory responses through its positive regulation on the posttranscriptional control of TNF- $\alpha$ and the cytokine expression under stress conditions, including I/R injury [28-30]. I/R injury is a common pathological condition that could cause acute inflammatory reaction, severe MOF, and even mortality [31]. After transferred to the nucleus under stress conditions, p38 MAPK could activate the phosphorylation of the downstream genes, facilitating the expression of genes relevant to the regulation of multiple transcription factors [32, 33]. Besides, due to target genes of the p38 MAPK signaling pathway participating in the regulation of various cellular responses, p38 MAPK signaling pathway might play a dominant role in multiple cellular regulations [34]. See that the p38 MAPK expression was elevated in tissues undergoing MOF, we confirmed that the p38 MAPK pathway was activated in such pathological condition. With comprehensive consideration of our results and previous research, we speculate that the suppression of p38 MAPK signaling pathway could alleviate tissue damage in MOF through molecular mechanisms [35], which contributed to the p38 MAPK signaling pathway being a potential novel target for the treatment of MOF.

The overproduction of various cytokines has been reported to participate in the aggravation of acute disorder, among which endotoxemia was demonstrated to contribute to the development and progression of MOF $[12,36]$. Thus the restore of cytokine balance by inhibiting the overproduction of both pro- and anti-inflammatory cytokines is considered important in treatment of MOF [37]. Recently, blood purifying technique has shed lights on the treatments of MOF and other critical illnesses due to its critical capabilities of removing toxic substances and inflammatory cytokines as well as maintaining the stability of hemodynamics [15]. As data above, cytokine signaling, cellular stress response, and inflammatory cytokine production might result from the activation of the p38 MAPK signaling pathway [38]. Therefore, we resumed that CBP treatment might regulate the expression of the p38 MAPK signaling pathway via some specific cytokines, and finally ameliorate the symptoms of MOF. Our results have proved our hypothesis, where the p38 MAPK signaling pathway was suppressed during CBP treatment in the MOF rats. However, precise mechanisms still need to be further clarified in the future.

Previous studies have also documented that the p38 MAPKsignaling pathway participates in acute disorder through the regulation of inflammatory cytokines [29, 39]. To further explore related mechanisms, iNOS expression and serum nitric oxide levels were analyzed in our experiment. The expression of iNOS and serum nitric oxide levels were initially elevated by endotoxin injection during the establishment of MOF model [11]. The inhibition of nNOS activity at resuscitation protected rats against the MOF and vascular dysfunction through the reduction of the levels of pro-inflammatory cytokines TNF- $\alpha$ and IL- 6 in hemorrhagic shock rats [40]. Similarly, we found that the serum nitric oxide levels and iNOS expression in liver, kidney, and lung tissues of rats were attenuated after CBP treatment, consequently leading to the amelioration of MOF. However, little is known about the potential roles of iNOS 


\section{Kidney Bloód Pressure Research}

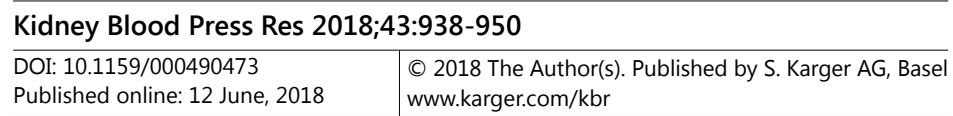

Ling et al.: Effects of CBP on MOF in Rats

in vascular decompensation and inflammation associated with MOF, which still needs more investigation in further study.

\section{Conclusion}

Our study provides evidences that CBP might ameliorate MOF through the suppression of the expressions of p38 MAPK signaling pathway and iNOS, as well as the downregulation of serum nitric oxide levels. Our findings revealed that CBP confers potential protective effect on MOF. Besides, these results provided further rational basics for the promotion of MOF therapies in some clinical conditions. However, results of this study were still limited due to the complicated relationship between the regulation of MOF and cytokine signaling, cellular stress response, as well as inflammatory cytokine production. Further investigations are needed to support the findings as well as to explore other underlying mechanisms.

\section{Acknowledgements}

We would like to acknowledge the helpful comments on this paper received from our reviewers.

\section{Disclosure Statement}

We declare that we have no conflicts of interest.

\section{References}

$>1$ Kotsovolis G, Kallaras K: The role of endothelium and endogenous vasoactive substances in sepsis. Hippokratia 2010;14:88-93.

-2 Minei JP, Cuschieri J, Sperry J, Moore EE, West MA, Harbrecht BG, O’Keefe GE, Cohen MJ, Moldawer LL, Tompkins RG, Maier RV, Inflammation, the Host Response to Injury Collaborative Research P: The changing pattern and implications of multiple organ failure after blunt injury with hemorrhagic shock. Crit Care Med 2012;40:1129-1135.

-3 Barut F, Ozacmak VH, Turan I, Sayan-Ozacmak H, Aktunc E: Reduction of Acute Lung Injury by Administration of Spironolactone After Intestinal Ischemia and Reperfusion in Rats. Clin Invest Med 2016;39:E15-24.

4 Zhao L, Luo L, Chen J, Xiao J, Jia W, Xiao Y: Utilization of extracorporeal membrane oxygenation alleviates intestinal ischemia-reperfusion injury in prolonged hemorrhagic shock animal model. Cell Biochem Biophys 2014;70:1733-1740.

-5 Baylis JR, St John AE, Wang X, Lim EB, Statz ML, Chien D, Simonson E, Stern SA, Liggins RT, White NJ, Kastrup CJ: Self-Propelled Dressings Containing Thrombin and Tranexamic Acid Improve Short-Term Survival in a Swine Model of Lethal Junctional Hemorrhage. Shock 2016;46:123-128.

-6 Liberatore AM, Moreira FC, Gomes TA, Menchaca-Diaz JL, Koh IH: Typical and atypical enteropathogenic Escherichia coli bacterial translocation associated with tissue hypoperfusion in rats. Braz J Med Biol Res 2011;44:1018-1024.

-7 Katsumi H, Fukui K, Sato K, Maruyama S, Yamashita S, Mizumoto E, Kusamori K, Oyama M, Sano M, Sakane T, Yamamoto A: Pharmacokinetics and preventive effects of platinum nanoparticles as reactive oxygen species scavengers on hepatic ischemia/reperfusion injury in mice. Metallomics 2014;6:1050-1056.

8 Guo C, Yang M, Jing L, Wang J, Yu Y, Li Y, Duan J, Zhou X, Li Y, Sun Z: Amorphous silica nanoparticles trigger vascular endothelial cell injury through apoptosis and autophagy via reactive oxygen species-mediated MAPK/Bcl-2 and PI3K/Akt/mTOR signaling. Int J Nanomedicine 2016;11:5257-5276. 


\section{Kidney \\ Blood Pressure Research}

Ling et al.: Effects of CBP on MOF in Rats

-9 Lee H, Ko EH, Lai M, Wei N, Balroop J, Kashem Z, Zhang M: Delineating the relationships among the formation of reactive oxygen species, cell membrane instability and innate autoimmunity in intestinal reperfusion injury. Mol Immunol 2014;58:151-159.

10 Guo WA: The search for a magic bullet to fight multiple organ failure secondary to ischemia/reperfusion injury and abdominal compartment syndrome. J Surg Res 2013;184:792-793.

11 McGown CC, Brown NJ, Hellewell PG, Brookes ZL: ROCK induced inflammation of the microcirculation during endotoxemia mediated by nitric oxide synthase. Microvasc Res 2011;81:281-288.

$\$ 12$ Helal GK: Thymoquinone supplementation ameliorates acute endotoxemia-induced liver dysfunction in rats. Pak J Pharm Sci 2010;23:131-137.

13 Harrois A, Hamada SR, Duranteau J: Fluid resuscitation and vasopressors in severe trauma patients. Curr Opin Crit Care 2014;20:632-637.

14 Damiani E, Adrario E, Luchetti MM, Scorcella C, Carsetti A, Mininno N, Pierantozzi S, Principi T, Strovegli D, Bencivenga R, Gabrielli A, Romano R, Pelaia P, Ince C, Donati A: Plasma free hemoglobin and microcirculatory response to fresh or old blood transfusions in sepsis. PLoS One 2015;10:e0122655.

15 Yuan H, Chen S, Hu F, Zhang Q: Efficacy of Two Combinations of Blood Purification Techniques for the Treatment of Multiple Organ Failure Induced by Wasp Stings. Blood Purif 2016;42:49-55.

-16 Yang M, Chen XM, Du XG, Cao FF, Vijaya Luxmi S, Shen Q: Continuous blood purification ameliorates endothelial hyperpermeability in SAP patients with MODS by regulating tight junction proteins via ROCK. Int J Artif Organs 2013;36:700-709.

17 Lou Z, Ren T, Peng X, Sun Y, Jiao G, Lu Q Zhang S, Lu X, Guo W: Bortezomib induces apoptosis and autophagy in osteosarcoma cells through mitogen-activated protein kinase pathway in vitro. J Int Med Res 2013;41:1505-1519.

18 Hommo T, Pesu M, Moilanen E, Korhonen R: Regulation of Inflammatory Cytokine Production by MKP-5 in Macrophages. Basic Clin Pharmacol Toxicol 2015;117:96-104.

19 Yang G, Li T, Xu J, Peng X, Liu L: Mitogen-activated protein kinases regulate vascular reactivity after hemorrhagic shock through myosin light chain phosphorylation pathway. J Trauma Acute Care Surg 2013;74:1033-1043.

20 Li G, Qian W, Zhao C: Analyzing the anti-ischemia-reperfusion injury effects of ginsenoside Rb1 mediated through the inhibition of p38alpha MAPK. Can J Physiol Pharmacol 2016;94:97-103.

-21 Ashraf MI, Ebner M, Wallner C, Haller M, Khalid S, Schwelberger H, Koziel K, Enthammer M, Hermann M, Sickinger S, Soleiman A, Steger C, Vallant S, Sucher R, Brandacher G, Santer P, Dragun D, Troppmair J: A p38MAPK/MK2 signaling pathway leading to redox stress, cell death and ischemia/reperfusion injury. Cell Commun Signal 2014;12:6.

-22 Neuder LE, Keener JM, Eckert RE, Trujillo JC, Jones SL: Role of p38 MAPK in LPS induced pro-inflammatory cytokine and chemokine gene expression in equine leukocytes. Vet Immunol Immunopathol 2009;129:192199.

23 Schmidt SB, Rollnik JD: Critical illness polyneuropathy (CIP) in neurological early rehabilitation: clinical and neurophysiological features. BMC Neurol 2016;16:256.

-24 Gharib SA, Mar D, Bomsztyk K, Denisenko O, Dhanireddy S, Liles WC, Altemeier WA: System-Wide Mapping of Activated Circuitry in Experimental Systemic Inflammatory Response Syndrome. Shock 2016;45:148156.

-25 Zhang J, Yuan C, Hua G, Tong R, Luo X, Ying Z: Early gut barrier dysfunction in patients with severe acute pancreatitis: attenuated by continuous blood purification treatment. Int J Artif Organs 2010;33:706-715.

-26 Du XG, Chen XM, Gan H, Li ZR, Wen YJ, Wang XC: Continuous blood purification ameliorates RhoAmediated endothelial permeability in severe acute pancreatitis patients with lung injury. Int J Artif Organs 2011;34:348-356.

27 Jia F, Rong P, Li D, Wang S, Jing Y, Ge Y, Meng J: The effect of continuous blood purification on the prognosis of cardiorenal syndrome patients. Cell Biochem Biophys 2015;71:957-961.

28 Menon MB, Gaestel M: TPL2 meets p38MAPK: emergence of a novel positive feedback loop in inflammation. Biochem J 2016;473:2995-2999.

29 Sun HY, Hu KZ, Yin ZS: Inhibition of the p38-MAPK signaling pathway suppresses the apoptosis and expression of proinflammatory cytokines in human osteoarthritis chondrocytes. Cytokine 2017;90:135143. 


\section{Kidney \\ Blood Pressure Research}

Kidney Blood Press Res 2018;43:938-950
\begin{tabular}{l|l} 
DOI: $10.1159 / 000490473$ & (c) 2018 The Author(s). Published by S. Karger AG, Basel
\end{tabular}

Publisned ontIne: IL June, 2018 www.karger.com/kbr

Ling et al.: Effects of CBP on MOF in Rats

-30 Kang KA, Wang ZH, Zhang R, Piao MJ, Kim KC, Kang SS, Kim YW, Lee J, Park D, Hyun JW: Myricetin protects cells against oxidative stress-induced apoptosis via regulation of PI3K/Akt and MAPK signaling pathways. Int J Mol Sci 2010;11:4348-4360.

-31 Konig K, Granja T, Eckle VS, Mirakaj V, Kohler D, Schlegel M, Rosenberger P: Inhibition of Plexin C1 Protects Against Hepatic Ischemia-Reperfusion Injury. Crit Care Med 2016;44:e625-632.

-32 Yang Q Li W, She H, Dou J, Duong DM, Du Y, Yang SH, Seyfried NT, Fu H, Gao G, Mao Z: Stress induces p38 MAPK-mediated phosphorylation and inhibition of Drosha-dependent cell survival. Mol Cell 2015;57:721734.

-33 Wehner S, Straesser S, Vilz TO, Pantelis D, Sielecki T, de la Cruz VF, Hirner A, Kalff JC: Inhibition of p38 mitogen-activated protein kinase pathway as prophylaxis of postoperative ileus in mice. Gastroenterology 2009;136:619-629.

34 Li B, Wang Z, Hu Z, Zhang M, Ren Z, Zhou Z, Huang J, Hu X: P38 MAPK Signaling Pathway Mediates Angiotensin II-Induced miR143/145 Gene Cluster Downregulation during Aortic Dissection Formation. Ann Vasc Surg 2017;40:262-273.

-35 Li Y, Xu B, Xu M, Chen D, Xiong Y, Lian M, Sun Y, Tang Z, Wang L, Jiang C, Lin Y: 6-Gingerol protects intestinal barrier from ischemia/reperfusion-induced damage via inhibition of p38 MAPK to NF-kappaB signalling. Pharmacol Res 2017;119:137-148.

36 He L, Wang B, Yao Y, Su M, Ma H, Jia N: Protective effects of the SEPS1 gene on lipopolysaccharide-induced sepsis. Mol Med Rep 2014;9:1869-1876.

-37 Kobe Y, Oda S, Matsuda K, Nakamura M, Hirasawa H: Direct hemoperfusion with a cytokine-adsorbing device for the treatment of persistent or severe hypercytokinemia: a pilot study. Blood Purif 2007;25:446453.

-38 Ehlting C, Lai WS, Schaper F, Brenndorfer ED, Matthes RJ, Heinrich PC, Ludwig S, Blackshear PJ, Gaestel M, Haussinger D, Bode JG: Regulation of suppressor of cytokine signaling 3 (SOCS3) mRNA stability by TNFalpha involves activation of the MKK6/p38MAPK/MK2 cascade. J Immunol 2007;178:2813-2826.

39 Chen NN, Wei F, Wang L, Cui S, Wan Y, Liu S: Tumor Necrosis Factor Alpha Induces Neural Stem Cell Apoptosis Through Activating p38 MAPK Pathway. Neurochem Res 2016;41:3052-3062.

40 Sordi R, Chiazza F, Collino M, Assreuy J, Thiemermann C: Neuronal Nitric Oxide Synthase is Involved in Vascular Hyporeactivity and Multiple Organ Dysfunction Associated with Hemorrhagic Shock. Shock 2016;45:525-533. 